\title{
Editorial
}

\section{Hypercapnia during oxygen therapy in airways obstruction: a reappraisal}

Hypercapnia and acidosis after oxygen therapy in patients with acute exacerbations of chronic airways obstruction is well recognised, and an understanding of its pathogenesis is essential if successful strategies to limit the rise in arterial carbon dioxide tension $\left(\mathrm{PaCO}_{2}\right)$ are to be designed.

The acute rise in $\mathrm{PaCO}_{2}$ during oxygen therapy was first ascribed to reduced hypoxic drive (due to the rise in $\mathrm{PaO}_{2}$ ), an acquired insensitivity to carbon dioxide, and consequent hypoventilation. ${ }^{1}$ This led to the introduction by Campbell of controlled oxygen therapy to give hypoxic patients a small increase in arterial oxygen tension $\left(\mathrm{PaO}_{2}\right)$, sufficient to increase significantly the arterial oxygen saturation $\left(\mathrm{SaO}_{2}\right)$, but not to depress seriously the ventilatory drive. ${ }^{2}$ Other mechanisms for this oxygen induced hypercapnia were considered (table 1) but were originally thought to be playing only a minor part. Recently new experimental data ${ }^{3}$ in patients with acute respiratory failure have cast doubt on the classic explanation of hypoventilation. Instead, it was suggested that the rise in alveolar oxygen tension reduces the adaptatory pulmonary vasoconstriction that normally helps to maintain ventilation-perfusion $\left(\dot{V}_{\mathrm{A}} / \mathbf{Q}\right)$ matching. Thus a deterioration in $\dot{V}_{A} / Q$ matching rather than hypoventilation became the favoured explanation for the hypercapnia. Interpretation of data in this field is extremely difficult and there are inadequate experimental data available to prove one or other of these hypotheses.

The purpose of this article is to discuss the possible mechanisms of carbon dioxide retention after oxygen therapy and to re-examine the relevent data, particularly those of Aubier et $\mathrm{al}^{3}{ }^{3}$ The conclusions are at variance with those of some other authors-namely: (a) release of hypoxic vasoconstriction has a minimal effect; $(b)$ the major factor causing extra carbon dioxide retention is decreased hypoxic drive due to the rise in $\mathrm{PaO}_{2}$, as originally proposed; (c) the Haldane effect plays a smaller part in the steady state increase in $\mathrm{PaCO}_{2}$ than previously supposed.

Address for reprint requests: John R Stradling, Churchill Hospital, Oxford OX3 $7 \mathrm{LJ}$.
Table 1 Suggested causes of raised arterial carbon dioxide tension after oxygen therapy in patients with chronic airways obstruction

1 Hypoventilation from reduced hypoxic ventilatory drive due to the rise in arterial oxygen tension

2 Increased ventilation-perfusion mismatching

(a) loss of hypoxic vasoconstriction

(b) development of collapsed alveoli

3 Haldane effect-displacement of carbon dioxide from oxygenated blood

4 Reduced slope of the carbon dioxide content curve for blood as carbon dioxide tension rises-reduction in effective partition coefficient

Effect of oxygen during acute exacerbations of chronic airways obstruction

Although clinically it was well recognised that high inspired oxygen concentrations led to severe hypercapnia in acute exacerbations of chronic airways obstruction, it was not until 1980 that Aubier et al made comprehensive measurements of gas exchange in this condition. ${ }^{3}$

\section{METHODS}

Aubier $e$ al looked at 22 patients with chronic airways obstruction during an episode of acute on chronic respiratory failure. All were severely hypoxic and hypercapnic (table 2). Ventilation was measured with a mouthpiece, one way valve, and pneumotachograph (deadspace $75 \mathrm{ml}$ ). Ventilation, blood gases, mixed expired carbon dioxide, and cardiac output were measured before and at the end of 15 minutes of breathing $100 \%$ oxygen. The physiological deadspace $V_{D_{\text {phys }}}$ to tidal volume (VT) ratio was calculated from the simplified equation:

$$
\frac{\mathrm{VD}_{\text {phys }}}{\mathrm{VT}}=\frac{\left(\mathrm{PaCO}_{2}-\mathrm{P}_{\mathrm{E}} \mathrm{CO}_{2}\right)}{\mathrm{PaCO}_{2}},
$$

where $\mathrm{P}_{\mathrm{E}} \mathrm{CO}_{2}=$ mixed expired $\mathrm{CO}_{2}$ tension.

\section{RESULTS}

They found ${ }^{3}$ that, initially, overall ventilation fell by $18 \%$ but then rose to $93 \%$ of the control level during the 15 th minute of oxygen administration. Although the $7 \%$ fall in ventilation at the 15 th minute was 
Table 2 Data on gas exchange in patients studied by Aubier et al ${ }^{3}$ with acute on chronic respiratory failure before and after they had breathed $100 \%$ oxygen

\begin{tabular}{llcl}
\hline & Air & Oxygen & $\%$ change \\
\hline $\mathrm{PaCO}_{2} \mathrm{~mm} \mathrm{Hg} \mathrm{(kPa)}$ & $65(8 \cdot 7)$ & $88(11 \cdot 7)$ & +35 \\
$\dot{\mathrm{V}}(\mathrm{l} / \mathrm{min})$ & $10 \cdot 2$ & $9 \cdot 5$ & -7 \\
$\mathrm{f}(\mathrm{b} / \mathrm{min})$ & 32 & 31 & -3 \\
$\mathrm{VT}_{\mathrm{T}}(\mathrm{ml})$ & 341 & 323 & -6 \\
$\mathrm{VD}_{\text {phys }} / \mathrm{VT}(\%)$ & 77 & 82 & +6 \\
\hline
\end{tabular}

$\mathrm{PaCO}_{2}$-arterial carbon dioxide tension; $\dot{\mathrm{V}}$-minute ventilation; $\mathrm{f}$-breathing frequency; VT-tidal volume;

$\mathrm{VD}_{\text {phys }}$ - physiological deadspace.

significant, neither the frequency nor the VT changes responsible for this fall reached statistical significance. $\mathrm{PaCO}_{2}$ rose by $23 \mathrm{~mm} \mathrm{Hg}(3.06 \mathrm{kPa})(35 \%)$, carbon dioxide production remained unchanged ( 270 versus $268 \mathrm{ml} / \mathrm{min}$ ), and cardiac output rose slightly from $7 \cdot 2$

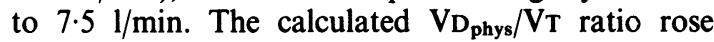
significantly from $77 \%$ to $82 \%$ ( $<<0.01$ ).

\section{CONCLUSIONS}

Aubier et al concluded that most of the rise in $\mathrm{PaCO}_{2}$ was due to a deterioration in $\dot{\mathrm{V}}_{\mathrm{A}} / \mathrm{Q}$ matching, on the basis of the following statements. (1) $\dot{V E}$ fell only $7 \%$ and thus could account for only $5 \mathrm{~mm} \mathrm{Hg}(0.66 \mathrm{kPa})$ of the rise in $\mathrm{PaCO}_{2}$. (2) The Haldane effect calculated from Lenfant's nomogram ${ }^{4}$ accounted for $7 \mathrm{~mm} \mathrm{Hg}$ $(0.93 \mathrm{kPa})$. (3) There was a significant rise in $\mathrm{VD}_{\text {phys }} / \mathrm{VT}$ and, since VT did not change significantly, $V_{D_{\text {phys }}}$ must have changed. Thus $\dot{V}_{A} / Q$ matching in the lungs must have worsened.

\section{CRITIQUE}

These statements are probably incorrect deductions from the data provided for the following reasons.

The conversion of changes in overall ventilation to expected changes in $\mathrm{PaCO}_{2}$ is extremely difficult and depends on certain assumptions. The classic way is via the formula

$\mathrm{PaCO}_{2}=\frac{\mathrm{k} \cdot \dot{\mathrm{V}} \mathrm{CO}_{2}}{\mathrm{f} \times\left(\mathrm{VT}-\mathrm{VD}_{\left.\mathrm{p}_{\text {phy }}\right)}\right.}$ or $\frac{\mathrm{k} \cdot \dot{\mathrm{V}} \mathrm{CO}_{2}}{\mathrm{~V} \mathrm{E} \times\left(1-\mathrm{VD}_{\mathrm{D}_{\text {phys }} / \mathrm{VT}}\right)}$, where $\mathrm{k}=\mathrm{a}$ constant, $\dot{\mathrm{VCO}}_{2}=$ carbon dioxide production, $f=$ frequency. With this approach, and Aubier's data, the calculated $V_{D_{\text {phys }}}$ is $263 \mathrm{ml}(341 \times$ $0.77)$ for air and $265 \mathrm{ml}(323 \times 0.82)$ for oxygen. Hence $V_{D_{\text {phys }}}$ did not change at all. The $\mathrm{VD}_{\mathrm{D}_{\text {phys }} / \mathrm{VT}}$ ratio rose only because $V_{T}$ fell and the error made was to assume that a statistically insignificant change could not be physiologically important.

The problem with this approach is in trying to interpret changes in $\mathrm{VD}_{\text {phys }} / \mathrm{VT}$ (or just $\mathrm{VD}_{\text {phys }}$ ) to indicate changes in $\dot{V} / Q$ matching in the face of changing VT. In normal subjects $V_{D_{\text {phys }}}$ falls a little as $V_{T}$ falls. In patients with stable chronic airways obstruction
$\mathrm{VD}_{\text {phys }}$ falls more with a fall in VT than in normal subjects, but this proportion is very variable. ${ }^{5}$ The higher $\dot{\mathrm{V}} / \mathbf{Q}$ units contribute most to the change in के $V_{D_{\text {phys }}}$ with VT. ${ }^{5}$ Thus in Aubier's experiment a small $\vec{\circ}$ fall in $V D_{\text {phys }}$ might have been expected with the fall in $V_{T}$ if $\dot{V}_{A} / Q$ matching had remained unchanged. There $\vec{\omega}$ are, however, no relevant control data for estimating this fall except from patients with stable chronic air- $\times$ ways obstruction, whose tidal volumes tend to be $\nexists$ higher. Read and Lee ${ }^{5}$ show that, on average, $V_{D_{\text {phys }}} \overrightarrow{\vec{N}}$ falls $0.4 \mathrm{ml}$ with each $1 \mathrm{ml}$ fall in VT in patients with stable chronic airways obstruction. Presumably in the

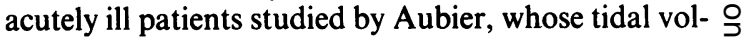
umes were closer to their anatomical-plus-instrument deadspaces, the physiological deadspaces could not ${ }_{D}$ have fallen much further. Nevertheless, from the data $\overbrace{\varnothing}$ of Read and Lee, which probably overestimate, the $V_{D_{\text {phys }}}$ in Aubier's experiment might have been $\mathbb{\Phi}$ expected to fall to $256 \mathrm{ml}(263-0.4 \times(341-323))$ had there been no change in $\dot{V}_{A} / Q$ matching. So $60 \%$ of the rise in $\mathrm{PaCO}_{2}$ after administration of oxygen can be ascribed to a fall in ventilation and $40 \%$ to a deterioration in $\dot{V}_{A} / Q$ matching because the actual $V_{D_{\text {phys }}}$ was $265 \mathrm{ml}$, compared with a predicted value of $\overline{0}$ $256 \mathrm{ml}$. If the Haldane effect and slope change of the

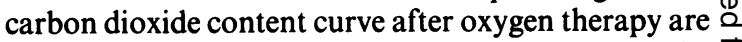
considered they would also be expected to raise the $\overrightarrow{\overrightarrow{0}}$

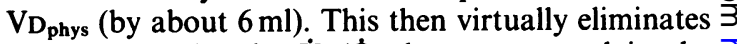
any need to invoke $\dot{\mathrm{V}}_{\mathrm{A}} / \mathbf{Q}$ changes to explain the observed rise in $\mathrm{PaCO}_{2}$.

Using the simpler approach favoured by West $^{6}$ in analysing this sort of problem, we come to the same conclusions. If we assume that the anatomical dead- $x$ spaces in Aubier's patients were on average about $\frac{5}{3}$ $175 \mathrm{ml}$ (mean age of patient 65 years) and add the

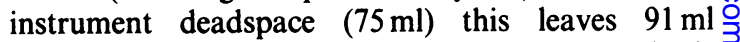
(341-250) as the VT reaching th: alveoli. On the basis of the equation

$$
\dot{V}_{A}=f\left[V T-\left(V_{D_{\text {anatomical }}} \text { and } V_{D_{\text {instrumental }}}\right)\right]
$$

the $\dot{V}_{A}$ with air becomes $2.911 / \mathrm{min}$ and with oxygen $2.26 \mathrm{l} / \mathrm{min}^{-1}$, a fall of $22 \%$. This would be expected to $\mathrm{N}$ raise the $\mathrm{PaCO}_{2}$ from 65 to $84 \mathrm{~mm} \mathrm{Hg}(8.6$ to $11.2 \mathrm{kPa})$, N leaving only a further $4 \mathrm{~mm} \mathrm{Hg}(0.53 \mathrm{kPa})$ to be expla- 요 ined by other mechanisms. The figure shows how as $\omega$ the initial $\mathrm{PaCO}_{2}$ rises smaller and smaller falls in $\dot{\mathrm{V}}_{\mathrm{A}} \stackrel{2}{2}$ are required to produce a given further rise in $\mathrm{PaCO}_{2}$. This is an obvious point but one often forgotten. In $ळ$ addition, because the tidal volumes of the acutely ill ${ }_{-}^{+}$ patients in Aubier's study were so small and thus close $\frac{0}{0}$ to the total deadspace, only very small falls in VT were $\stackrel{\mathbb{D}}{\mathbb{D}}$ necessary to produce a physiologically significant fall $\frac{\Omega}{\mathrm{D}}$ in $\mathrm{VA}^{\prime}$.

The data of Aubier et $a l^{3}$ actually lend mora? support to the hypothesis that hypoventilation is the cause of the hypercapnia than to the hypothesis that increasing $V_{A} / Q$ mismatch is responsible. 


\section{$\mathrm{Paco}_{2}$ $(\mathrm{mm} \mathrm{Hg})$}

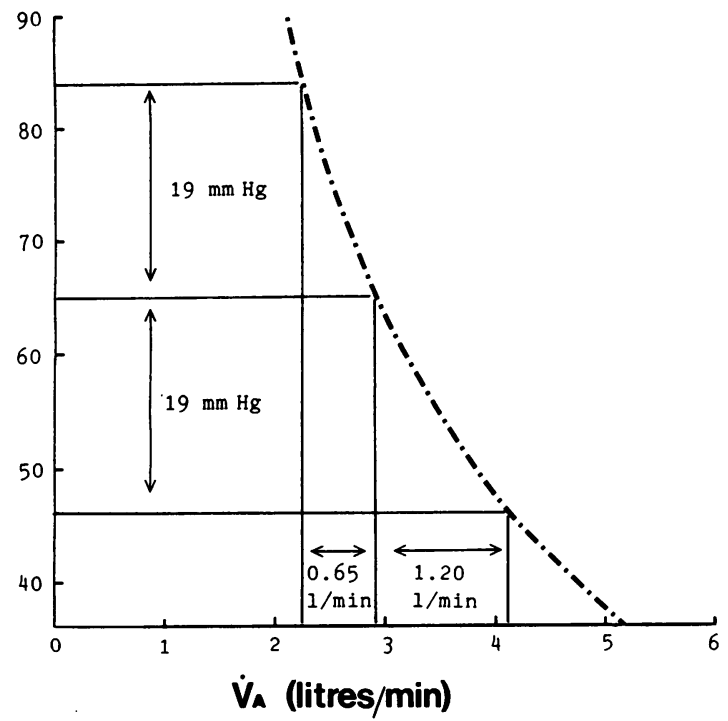

Relationship between alveolar ventilation $\left(\dot{V}_{A}\right)$ and arterial carbon dioxide tension $\left(\mathrm{PaCO}_{2}\right)$ based on the data of Aubier et al. ${ }^{3}$ Carbon dioxide production $=270 \mathrm{ml}$. As the initial $\mathrm{PaCO}_{2}$ rises, smaller decreases in $\dot{V}_{A}$ are required to produce the same rise in $\mathrm{PaCO}_{2}$.

Conversion: traditional to SI units- $\mathrm{PaCO}_{2}: 1 \mathrm{~mm} \mathrm{Hg}=$ $0.133 \mathrm{kPa}$.

Are data from patients with stable chronic airways obstruction relevant in acute exacerbations?

It has been stated that patients with chronic airways obstruction respond differently to oxygen therapy depending on whether they are stable or in acute respiratory failure. ${ }^{7}$ This is based largely on the observation that $\mathrm{PaCO}_{2}$ tends to rise more during oxygen therapy in acute respiratory failure than it does in chronic respiratory failure. For several reasons it seems unnecessary to invoke any essential differences.

The $\dot{V}_{A} / Q$ mismatch of chronic airways obstruction (plus the lack of an adequate ventilatory response to the retained carbon dioxide) can reduce $\mathrm{PaO}_{2}$ to levels that will stimulate ventilation. Breathing is thus mainly sustained in these patients by a mixture of normal or depressed oxygen and carbon dioxide drives. If $\mathrm{PaO}_{2}$ is then raised by oxygen therapy, part of the drive to breathe may be lost, ventilation may fall, and the carbon dioxide level will then slowly rise. The lower the initial $\mathrm{PaO}_{2}$ (as in an exacerbation) then the greater will be the loss of hypoxic drive when the inspired oxygen concentration is increased. As already discussed, the increase in $\mathrm{PaCO}_{2}$ will depend on the fall in alveolar ventilation and the initial $\mathrm{PaCO}_{2}$ rather than the overall ventilation. If the breathing pattern is rapid and shallow (as in an exacerbation) then a small fall in VT represents a large fall in alveolar ventilation, and if the $\mathrm{PaCO}_{2}$ is already raised then a given fall in $\dot{V}_{A}$ will produce a larger absolute rise in $\mathrm{PaCO}_{2}$ than if it had been initially lower (figure).

The degree to which this rise in $\mathrm{PaCO}_{2}$ is limited by the stimulation of ventilation depends on carbon dioxide sensitivity in the brainstem, the initial $\mathrm{PaCO}_{2}$, and the capacity of the respiratory muscles to respond to increased drive, versus the impairment of the mechanics of the respiratory system. Since the centres in the brainstem responsible for carbon dioxide drive probably respond to changes in hydrogen ion concentration $\left[\mathrm{H}^{+}\right],{ }^{8}$ bigger changes in $\mathrm{PaCO}_{2}$ are required to produce changes in ventilation when the $\mathrm{PaCO}_{2}$ is already high and compensated for:

$$
\dot{\mathrm{V}} \propto\left[\mathrm{H}^{+}\right] \propto \mathrm{PCO}_{2} /\left[\mathrm{HCO}_{3}{ }^{-}\right]
$$

On the basis of these considerations alone, without the need to invoke different $\left[\mathrm{H}^{+}\right]$sensitivities, patients with high breathing frequencies, low tidal volumes, low $\mathrm{PaO}_{2}$, and already high $\mathrm{PaCO}_{2}$ (all features of an acute exacerbation of chronic airways obstruction) would be expected to have the biggest changes in $\mathrm{PaCO}_{2}$ after any reduction in hypoxic drive from oxygen therapy. Two groups have found the rises in $\mathrm{PaCO}_{2}$ after oxygen therapy in stable chronic obstructive lung disease to correlate well with the initial degree of hypoxia and hypercapnia. ${ }^{910}$

These considerations suggest that the data on hypercapnia after oxygen therapy derived from patients with stable chronic obstructive lung disease might be relevant to acute exacerbations since there is no reason to believe that the underlying mechanisms are any different.

\section{EFFECT OF OXYGEN ON PATIENTS WITH}

\section{STABLE CHRONIC OBSTRUCTIVE LUNG DISEASE}

Measuring minute ventilation $(\dot{V} E)$ and $\dot{V}_{A} / Q$ during oxygen therapy presents its own problems. Furthermore, mouthpieces alter ventilation ${ }^{1112}$ and may mask oxygen induced hypoventilation, as occurs in patients with acute asthma. ${ }^{13}$ The use of surface measurements to estimate ventilation is unfortunately considerably less accurate. ${ }^{14}$

Lee and Read ${ }^{15}$ have performed extensive studies on 58 patients with stable chronic airways obstruction, using changes in $\mathrm{VD}_{\text {phys }} / \mathrm{VT}$ ratios to estimate changes in $\dot{V}_{A} / Q$ distribution after $100 \%$ oxygen therapy. They found variable rises in $\mathbf{V D}_{\text {phys }} / V_{T}$ ratios accompanied by falls in VT. Using their control data ${ }^{5}$ of $\mathrm{VD}_{\text {phys }}$ changes with $\mathrm{VT}(0.4$ (SD 0.2$) \mathrm{ml}$ per $\left.\mathrm{ml} \mathrm{VT}\right)$

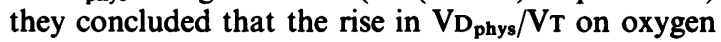
was a little more than could be accounted for by the 
fall in VT. Unfortunately no allowance was made for the rise in $V_{D_{\text {phys }}}$ due to the Haldane effect or the rise in $\mathrm{PaCO}_{2}$ itself (see below).

Horsfield et al $^{16}$ found a $10 \%$ rise in $\mathrm{PaCO}_{2}$ and an accompanying $8 \%$ fall in ventilation in 17 patients with chronic airways obstruction after $80 \%$ oxygen breathing. There was also pulmonary vasodilation (cardiac output unchanged) but this was presumably not specifically in low $\dot{V} / Q$ areas since the efficiency of carbon dioxide excretion was not affected. Using a gamma camera and nitrogen-13, Eiser et al ${ }^{17}$ demonstrated a small but significant redistribution of blood flow in six of 16 patients with chronic airways obstruction given $30 \%$ oxygen. The effect of this on gas exchange, however, was calculated to be inadequate to produce a rise in $\mathrm{PaCO}_{2}$. Using a similar technique but longer equilibration times, Guenard et al ${ }^{18}$ found no redistribution of blood flow in 17 patients with chronic airways obstruction breathing $30 \%$ oxygen, but noted a tendency for the overall reduction in ventilation observed $(9.4 \%, p<0.05)$ to be mainly in the low $\dot{\mathrm{V}}_{\mathrm{A}} / \bar{Q}$ areas. Thirty minutes after a period of breathing about $60 \%$ oxygen Rudolf et al ${ }^{19}$ found a $3 \mathrm{~mm} \mathrm{Hg}$ increase in alveolar-arterial gradient for oxygen $\left(\mathrm{PaCO}_{2}\right.$ was unchanged) in 18 patients with airways obstruction. This small change, which was taken as evidence for persisting deterioration in $\dot{V}_{A} / Q$ matching, could also have been due to a change in respiratory quotient of as little as 0.04 (which was not measured). Using an inert gases technique for measuring $\dot{V}_{A} / Q$ matching in 23 patients with chronic airways obstruction, Wagner et al ${ }^{20}$ were unable to document any consistent effect of $100 \%$ oxygen on either $\dot{V}_{A} / Q$ distribution or conversion of low $\dot{V}_{A} / Q$ units to shunt as predicted and found in normal subjects. ${ }^{21}$ Using the same inert gases technique, Castaing $e a^{22}$ studied the effect of $26 \%$ oxygen on $\dot{V}_{A} / Q$ matching in 14 patients with stable chronic airways obstruction. They found a small but consistent shift of blood flow to low $\dot{V}_{A} / Q$ units, suggesting release of hypoxic vasoconstriction. The rise in $\mathrm{PaCO}_{2}(1 \cdot 7 \%)$ was not significant, neither were the small falls in overall ventilation and cardiac output.

In another study 12 patients with stable chronic airways obstruction were observed by means of surface measurements of ventilation and a $7 \%$ fall in ventilation was found after they had breathed $50 \%$ oxygen. ${ }^{23}$ This fall was theoretically sufficient to explain the associated $7 \%$ rise in $\mathrm{PaCO}_{2}$. Without a mouthpiece, however, carbon dioxide production could not be measured, and this limits the extent to which the data can be interpreted.

In summary, studies on patients with stable disease have failed to show an effect of raising inspired oxygen concentration on $V_{A} / Q$ matching that is large enough to raise $\mathrm{PaCO}_{2}$ significantly.

\section{Other mechanisms raising $\mathrm{PaCO}_{2}$ after oxygen therapy}

\section{THE HALDANE EFFECT}

The carbon dioxide content curve for blood depends

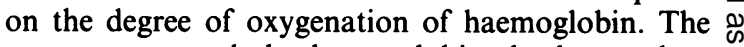
more oxygenated the haemoglobin the less carbon dioxide can be carried at a given $\mathrm{PCO}_{2}$; this produces a parallel shift of the relationship between $\mathrm{PCO}_{2}$ and the carbon dioxide content of blood (that is, the slope is unchanged) over the normal range of $\mathrm{PCO}_{2}$ and $\times$ above. Thus if a hypoxaemic patient is given oxygen, $\stackrel{A}{A}$ the rise in arterial and venous oxygen saturation will cause carbon dioxide to be evolved and the $\mathrm{PCO}_{2}$ will rise (for example, by $6 \mathrm{~mm} \mathrm{Hg}(0.8 \mathrm{kPa})$ when $\mathrm{PaCO}_{2}$ is $65 \mathrm{~mm} \mathrm{Hg}(8.7 \mathrm{kPa}))$ and oxygen saturation will go from $70 \%$ to $100 \%{ }^{13}$ Christiansen et al first described this effect ${ }^{24}$ and Lenfant ${ }^{4}$ drew up a nomogram based on in vitro, closed system data, ${ }^{25}$ using only the change in saturation and the starting $\mathrm{PaCO}_{2}$ to predict the rise in $\mathrm{PaCO}_{2}$. It has been suggested that the Haldane effect, through this mechanism, accounts for a calculable increase in the steady state $\mathrm{PaCO}_{2}$ that follows the administration of oxygen. Although the Haldane effect does increase the $\mathrm{PaCO}_{2}$ by this mechanism, it does so only transiently. In a closed system the $\mathrm{PCO}_{2}$ will rise, because the evolved carbon dioxide cannot escape; in vivo the majority of the extra carbon dioxide is blown off via the lungs. This transient rise in carbon dioxide evolution, early on during oxygen therapy, will produce an initial instability of the $\mathrm{PaCO}_{2}$.

The Haldane effect does, however, influence carbon dioxide excretion from a non-homogeneous lung over the longer term in a subtle but smaller way. ${ }^{26}$ In gas exchange units with low $\dot{V} / \mathbf{Q}$, increasing inspired oxygen concentration will lead to bigger changes in oxygen saturation in capillary blood than in high $\dot{\mathbf{V}} / \mathbf{Q}$ units, where the blood is already well saturated. Thus more carbon dioxide will be evolved into these low $\dot{\mathrm{V}} / \mathbf{Q}$ alveoli because of the larger Haldane effect. Since ventilation to these alveoli is not increased, capillary $\mathrm{PCO}_{2}$, and hence $\mathrm{PaCO}_{2}$, must rise. This reduction in the matching of carbon dioxide evolution to alveolar $N$ ventilation, with a consequent wider spread of $\mathrm{PCO}_{2}$ O levels in the lung, will increase the alveolar-arterial $\tilde{O}$ gradient and physiological deadspace for carbon dioxide. As the magnitude of this effect depends on a complicated interaction between degree of $\dot{V} / \mathbf{Q}$ mismatch, haemoglobin concentrations, change in oxygenation, and starting $\mathrm{PaCO}_{2}$, it cannot be predicted $\stackrel{?}{+}$ from a simple nomogram. The West multi- $T$ compartment steady state model of gas exchange in the lung ${ }^{27}$ (set up with severe $\dot{V} / Q$ mismatch, a starting $\mathrm{PaCO}_{2}$ of $65 \mathrm{~mm} \mathrm{Hg}(8 \cdot 1 \mathrm{kPa})$, and a $30 \%$ change $\underset{\mathbb{Q}}{\mathbb{D}}$ in $\mathrm{SaO}_{2}$ ) demonstrates this effect, but it amounts to no more than a $3 \mathrm{~mm} \mathrm{Hg}(0.5 \mathrm{kPa})$ rise in $\mathrm{PaCO}_{2}$, about 
half of that predicted from Lenfant's nomogram. ${ }^{4}$ Less severe degrees of $\dot{V} / \dot{Q}$ mismatching would produce less than a $3 \mathrm{~mm} \mathrm{Hg}$ rise and be even less relevant clinically.

\section{REDUCED SLOPE OF $\mathrm{PCO}_{2}$-CARBON DIOXIDE} CONTENT CURve AS $\mathrm{PCO}_{2}$ Rises

Excretion of an inert gas from the lung depends on its effective partition coefficient. ${ }^{28}$ The less soluble a gas the fewer molecules will be excreted for a given mixed venous-alveolar pressure gradient. In a nonhomogeneous lung this effectively increases the physiological deadspace for that gas. Thus, because the relationship between $\mathrm{PCO}_{2}$ and carbon dioxide content of the blood flattens as $\mathrm{PCO}_{2}$ (or more correctly $\left.\left[\mathrm{H}^{+}\right]\right)$rises, the physiological deadspace will also rise, ${ }^{28}$ as will the ratio of deadspace to tidal volume $\left(V_{D_{\text {phys }}} / \mathrm{VT}\right)$ if $\mathrm{VT}$ is kept constant. This mechanism will therefore slightly amplify a $\mathrm{PaCO}_{2}$ rise caused by some other event. For example, a $\mathrm{PCO}_{2}$ rise from 65 to $88 \mathrm{~mm} \mathrm{Hg}(8 \cdot 1$ to $11 \cdot 1 \mathrm{kPa})$ reduces the effective partition coefficient from 0.5 to $0.4 \mathrm{ml} / 100 \mathrm{ml}$ blood $/ \mathrm{mm} \mathrm{Hg}$. This would change the $\mathrm{VD}_{\text {phys }} / \mathrm{VT}_{\mathrm{T}}$ ratio from $61.5 \%$ to $62.2 \%$ (a rise in $\mathrm{VD}_{D_{\text {phys }} \text { of about }}$ 2-3 ml). ${ }^{28}$ Bigger effects would be seen at normal or subnormal values of $\mathrm{PaCO}_{2}$, since the slope change with $\mathrm{PaCO}_{2}$ change is greater.

\section{Conclusions}

To understand the causes of hypercapnia that follows oxygen therapy in chronic airways obstruction is of clinical importance. Because the physiological arguments are complicated incorrect conclusions have been drawn. If the rise in $\mathrm{PaCO}_{2}$ after oxygen therapy was due predominantly to increasing $\dot{V}_{A} / Q$ mismatch and not hypoventilation, then the use of ventilatory stimulants in these circumstances would seem far less appropriate and perhaps likely to precipitate muscle fatigue. This would leave artificial ventilation as the only appropriate treatment for hypercapnia induced acidosis that was judged to be life threatening. If, however, the rise in $\mathrm{PaCO}_{2}$ after oxygen therapy is indeed due to a fall in global ventilation (and Campbell was right after all), then judicious use of ventilatory stimulants to reverse some of this fall becomes theoretically appropriate, particularly if this produces an increase in VT in preference to frequency.

I wish to express considerable gratitude to $\mathrm{Dr} A$ Slutsky and Dr J M B Hughes for the help given in the preparation of this article.

JOHN R STRADLING Osler Chest Unit Churchill Hospital Oxford $0 \times 37 \mathrm{LJ}$

\section{References}

1 Gelb AF, Klein E, Schiffman P, Lugliani R, Aronstan P. Ventilatory response and drive in acute and chronic obstructive pulmonary disease. Am Rev Respir Dis 1977;16:9-16.

2 Campbell EJM. A method of controlled oxygen administration which reduces the risk of carbon dioxide retention. Lancet 1960;ii:12-4.

3 Aubier M, Murciano D, Milic-Emili J, et al. Effects of the administration of $\mathrm{O}_{2}$ on ventilation and blood gases in patients with chronic obstructive pulmonary disease during acute respiratory failure. Am Rev Respir Dis 1980;122:747-54.

4 Lenfant $\mathrm{C}$. Arterial-alveolar difference in $\mathrm{PCO}_{2}$ during air and oxygen breathing. J Appl Physiol 1966;21: 1356-62.

5 Read J, Lee J. Effects of changes of tidal volume on dead space in obstructive lung disease. J Appl Physiol 1969;26:105-10.

6 West JB. Causes of carbon dioxide retention in lung disease. $N$ Engl J Med 1971;284:1232-6.

7 Rudolph M, Banks RA, Semple SJG. Hypercapnia during oxygen therapy in acute exacerbations of chronic respiratory failure. Lancet 1977;ii:483-6.

8 Pappenheimer J. The ionic composition of cerebral extracellular fluid and its relation to control of breathing. Harvey Lect 1967;61:71-94.

9 Bone RC, Pierce AK, Johnson RL. Controlled oxygen administration in acute respiratory failure in chronic obstructive pulmonary disease. Am J Med 1978;65: 896-902.

10 Lopez-Majano V, Dutton RE. Regulation of respiration during oxygen breathing in chronic obstructive lung disease. Am Rev Respir Dis 1973;108:232-40.

11 Askanazi J, Silverberg PA, Foster RJ, Hyman AI, Milic Emili J, Kinney JM. Effects of respiratory apparatus on breathing pattern. J Appl Physiol 1980;48:577-80.

12 Gilbert R, Auchincloss JH, Brodsky J, Boden W. Changes in tidal volume, frequency and ventilation induced by their measurement. $J$ Appl Physiol 1972;33:252-4.

13 Freedman AR, Mangura BT, Lavietes MH. Minute ventilation in asthma: enhancement by mouthpiece and depression by oxygen administration. Am Rev Respir Dis 1983;128:800-5.

14 Stradling JR, Chadwick GA, Quirk C, Phillips T. Respiratory inductance plethysmography: calibration techniques, their validation and the effects of posture. Bull Eur Physiopathol Respir 1985;21:317-24.

15 Lee J, Read J. Effect of oxygen breathing on distribution of pulmonary blood flow in chronic obstructive lung disease. Am Rev Respir Dis 1967;96:1173-80.

16 Horsfield K, Segel N, Bishop JM. The pulmonary circulation in chronic bronchitis at rest and during exercise breathing air and 80\% oxygen. Clin Sci 1968;43: 473-83.

17 Eiser NM, Jones HA, Hughes JMB. Effects of $30 \%$ oxygen on local matching of perfusion and ventilation in chronic airways obstruction. Clin Sci 1977;53:387-95.

18 Guenard H, Verhas M, Todd-Prokopek A, et al. Effects of oxygen breathing on regional distribution of venti- 
lation and perfusion in hypoxaemic patients with chronic lung disease. Am Rev Respir Dis 1982; 125:12-7.

19 Rudolf M, Turner JAM, Harrison BDW, Riordan JF, Saunders KB. Changes in arterial blood gases during and after a period of oxygen breathing in patients with chronic hypercapnic respiratory failure and in patients with asthma. Clin Sci 1979;57:389-96.

20 Wagner PD, Dantzger DR, Dueck R, Clausen JL, West JB. Ventilation-perfusion inequality in chronic obstructive pulmonary disease. J Clin Invest 1977; 59:203-16.

21 Wagner PD, Laravuso RB, Uhl RR, West JB. Continuous distributions of ventilation-perfusion ratios in normal subjects breathing air and $100 \% \mathrm{O}_{2} . \mathrm{J}$ Clin Invest 1974;54:54-68.

22 Castaing Y, Manier G, Guenard H. Effect of $26 \%$ oxygen breathing on ventilation and perfusion distribution in patients with COLD. Bull Eur Physiopathol Respir 1985;21:17-23.
23 Stradling JR, Chadwick GA. Hyperoxia-induced hypercapnia: hypoventilation or increased $\dot{\mathrm{V}} / \mathbf{Q}$ mismatch? Am Rev Respir Dis 1985;131:A67 (abstract).

24 Christiansen J, Douglas CG, Haldane JS. The absorption and dissociation of carbon dioxide by human blood J Physiol 1914;48:244-71.

25 Dill DB, Edwards HT, Consolazio WV. Blood as a $\vec{\circ}$ physicochemical system. XI: man at rest. $J$ Biol Chem 1937;118:635-48.

26 Bryan AC, Bentivoglio LG, Beerel F, MacLeish $\mathrm{H}$, Zidulko A, Bates DV. Factors affecting regional distribution of ventilation and perfusion in the lung. $J$ Appl Physiol 1964;19:395-402.

27 West JB. Ventilation-perfusion inequality and overall gas $\vec{N}$ exchange in computer models of the lung. Respir Physiol 1969;7:88-110.

28 Hlastala MP, Robertson HT. Inert gas elimination 음 characteristics of the normal and abnormal lung. J Appl Physiol 1978;44:258-66. 